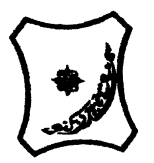

Bayero Journal of Pure and Applied Sciences, 10(1): 47 - 50

Received: April, 2017

Accepted: June, 2017

ISSN $2006-6996$

\title{
COMBINED EFFECT OF SODIUM VALPROATE AND ASCORBIC ACID ON PENTYLENETETRAZOLE-INDUCED SEIZURES IN MICE
}

\author{
Alhassan, A.W., ${ }^{1}$ Mohammed, D.K., ${ }^{1}$ Saleh, M.I.A., ${ }^{1}$ Mshelia, P.P., ${ }^{2}$ Yarube, I. U. ${ }^{3}$ and Lawan, I. ${ }^{4}$ \\ ${ }^{1}$ Department of Human Physiology, Faculty of Medicine, Ahmadu Bello University, ,Zaria. Kaduna State, \\ Nigeria. \\ ${ }^{2}$ Department of Human Physiology, College of Medical Sciences, Abubakar Tafawa Balewa University, Bauchi. \\ Bauchi State, Nigeria. \\ ${ }^{3}$ Department of Physiology, Faculty of Basic Medical Sciences, College of Health Sciences, Bayero University, \\ Kano. Kano State, Nigeria. \\ ${ }^{4}$ Department of Clinical Pharmacy, Faculty of Pharmaceutical Sciences, Ahmadu Bello University Zaria. Kaduna \\ State, Nigeria. \\ Corresponding author: abdulwhb2002@gmail.com
}

\begin{abstract}
ABSTRAC7
Epilepsy is one of the most frequent neurological afflictions characterized by excessive temporary neuronal discharges resulting in convulsion. The pathophysiology is still not fully understood. Even though oxidative stress has been implicated as one of the mechanisms, yet the management of convulsions do not take into cognizance the important role played by antioxidants. The aim of the study was to assess the combined effect of sodium valproate (conventional antiepileptic drug) and ascorbic acid (potent antioxidant) in pentylenetetrazole (PTZ) induced seizures. Thirty mice were divided into six groups of five each $(n=5)$. Group 1 served as control and administered normal saline $1 \mathrm{ml} / \mathrm{kg}$, group 2 received sodium valproate $200 \mathrm{mg} / \mathrm{kg}$, groups 3 and 4 were administered ascorbic acid (vitamin C) 100 $\mathrm{mg} / \mathrm{kg}$ and $300 \mathrm{mg} / \mathrm{kg}$, groups 5 and 6 were administered ascorbic acid (vitamin C) $100 \mathrm{mg} / \mathrm{kg}$ and $300 \mathrm{mg} / \mathrm{kg}$ respectively, in combination with sodium valproate $200 \mathrm{mg} / \mathrm{kg}, 15$ and 30 minutes prior to intra-peritoneal injection of PTZ (65 mg/kg). Seizure latency and duration were determined. The results showed that ascorbic acid alone has no effect on the seizure parameters. Sodium valproate $200 \mathrm{mg}$ had protective effect on PTZ-induced seizures. Combination of $300 \mathrm{mg} / \mathrm{kg}$ ascorbic acid with $200 \mathrm{mg} / \mathrm{kg}$ sodium valproate had a significant $(p<0.05)$ synergistic and marked protective effect, as indicated by increase in the latency of seizure and reduction in seizure duration as compared to the control. Anti-oxidant vitamin $C$ is recommended as co-treatment with sodium valproate in the management of seizures.

Keywords: Pentylenetetrazole, sodium valproate, ascorbic acid, seizures
\end{abstract}

\section{INTRODUCTION}

Epilepsy is one of the most frequent neurological afflictions in men and affects more than 60 million people worldwide (Nikalje, et al., 2012). It is characterized by spontaneous recurrent seizures (Jéssica et al., 2016). In spite of the availability of large numbers of antiepileptic drugs (AEDs) in the market, treatment of epilepsy still remains unsatisfactory and the basic neurophysiological and pathophysiology is still elusive. Adverse effects are the major limitations of AEDs (Shannon and Love, 2007; Weintraub et al., 2007). Pentylenetetrazole (PTZ) kindling is widely accepted as an experimental animal model for epileptogenesis and estimating the effectiveness of antiepileptic drugs (Morimoto et al., 2004). A cascade of biological events is reported to underlie the development and progression of epilepsy. Generation of reactive oxygen species in the brain is considered as one of the leading causes of generalized epilepsy associated with recurrent seizures (Sudha et al., 2001). Even though oxidative stress has been implicated as one of the mechanisms, yet most management do not take into cognizance the important role played by antioxidants. In oxidative stress, generation of free radicals called reactive oxygen species and reactive nitrogen species (ROS, RNS) result in oxidative damage to cellular protein, lipid and DNA and contribute to majority of seizures (Patil et al., 2011). Antiepileptic drugs, at least in part, impair antioxidant status of the body. The seizure activity during epilepsy decreases the antioxidant defense mechanism in the brain. The brain is particularly susceptible to oxidative stress because it utilizes the highest amount of oxygen compared with other bodily organs.

Exogenous antioxidants, like vitamins $E$ and $C$, inhibits the neuronal damage produced by lipid peroxidation during seizures (Barros et al., 2007). Current studies have suggested that antioxidant compounds may afford some level of neuroprotection against the neurotoxicity of seizures (Santos et al., 2009; Taufik, 2011). The aim of the study was to assess the combined effect of sodium valproate (conventional antiepileptic drug) and ascorbic acid (potent antioxidant) in pentylenetetrazole (PTZ) induced seizures. 


\section{MATERIALS AND METHODS}

The materials used for this experiment include, pentylenetetrazole (PTZ), sodium valproate, vitamin C, normal saline, syringes, conical flask, beakers, sample bottles, weighing machine and stop watch. Thirty male mice weighing $20-30 \mathrm{~g}$, fed with standard pelleted diet and water ad libitum, were divided into six groups of five mice each $(n=5)$. Group one served as a control and received normal saline $(1 \mathrm{ml} / \mathrm{kg})$, group two received sodium valproate $200 \mathrm{mg} / \mathrm{kg}$, group three were administered with ascorbic acid (Vitamin C) $100 \mathrm{mg} / \mathrm{kg}$, group four with ascorbic acid (Vitamin C) $300 \mathrm{mg} / \mathrm{kg}$, group five received ascorbic acid $100 \mathrm{mg} / \mathrm{kg}$ and sodium valproate $200 \mathrm{mg} / \mathrm{kg}$ and group six received ascorbic acid $300 \mathrm{mg} / \mathrm{kg}$ and sodium valproate $200 \mathrm{mg} / \mathrm{kg}$. These were administered 15 and 30 minutes before PTZ injection. Thirty minutes after the intra-peritoneal injection of PTZ (65 $\mathrm{mg} / \mathrm{kg}$ ), seizure latency, seizure duration and percentage protection were determined.

\section{STATISCAL ANALYSIS}

All data were expressed as mean \pm SEM and analysed using one-way analysis of variance (ANOVA) followed by Dunnett's test. Results were considered significant at $p<0.05$.

\section{RESULTS}

Table 1 showed the result of the combine effect of sodium valproate and ascorbic acid (administered 15 minutes before PTZ injection) on pentylenetrazoleinduced seizures in mice. It showed seizure latency for the combination of Vitamin C (300 $\mathrm{mg} / \mathrm{kg})$ and sodium valproate $(200 \mathrm{mg} / \mathrm{kg})$ significantly increased $(P<0.001)$ when compared to normal saline $(1 \mathrm{ml} / 100 \mathrm{~g})$ and sodium valproate $(200 \mathrm{mg} / \mathrm{kg})$, while the seizure duration reduced significantly when compared to normal saline $(P<0.001)$ and Sodium valproate $(P<0.05)$. The combination of Vitamin $C$ $(100 \mathrm{mg} / \mathrm{kg})$ and sodium valproate $(200 \mathrm{mg} / \mathrm{kg})$ completely protected the mice against seizure. Hind limb extension (HLE) occurred only in sodium valproate group.

Table 1: Combine effect of sodium valproate and ascorbic acid on pentylenetetrazole-induced seizures in mice (administered 15 minute before PTZ injection)

\begin{tabular}{lccc}
\hline Groups & $\begin{array}{c}\text { Seizure latency } \\
(\mathrm{Sec})\end{array}$ & $\begin{array}{c}\text { Seizure Duration } \\
(\mathrm{Sec})\end{array}$ & H.L.E \\
\hline Normal Saline $(1 \mathrm{ml} / 100 \mathrm{~g})$ & $137.5 \pm 19.8$ & $12.1 \pm 0.7$ & 0 \\
Sodium valproate $(200 \mathrm{mg} / \mathrm{kg})$ & $263.7 \pm 27.4$ & $10.5 \pm 2.0$ & 2 \\
Vitamin C $(100 \mathrm{mg} / \mathrm{kg})$ & $181.3 \pm 13.7$ & $13.3 \pm 0.8$ & 0 \\
Vitamin C $(300 \mathrm{mg} / \mathrm{kg})$ & $162.2 \pm 20.7$ & $12.9 \pm 1.8$ & 0 \\
Vitamin C $(100 \mathrm{mg} / \mathrm{kg})+$ Sodium & 0 & 0 & 0 \\
Valproate $(200 \mathrm{mg} / \mathrm{kg})$ & $\mathrm{a}$ ) & a**b* & \\
Vitamin C $(300 \mathrm{mg} / \mathrm{kg})+$ Sodium & $716.7 \pm 141$ & $2.4 \pm 1.3$ & 0 \\
Valproate $(200 \mathrm{mg} / \mathrm{kg})$ & &
\end{tabular}

${ }^{*} \mathrm{p}<0.05,{ }^{*} \mathrm{p}<0.001$ when compared to the control group. a and $\mathrm{b}$ represent significant differences with normal saline and sodium valproate respectively. H.L.E - Hind limb extension.

Table 2 showed the result of the combine effect of sodium valproate and ascorbic acid (administered 30 minutes before PTZ injection) on pentylenetetrazoleinduced seizures in mice. The combination of Vitamin
C $(300 \mathrm{mg} / \mathrm{kg})$ and Sodium valproate $(200 \mathrm{mg} / \mathrm{kg})$ completely protected the mice against all seizure parameters. Hind limb extension occurred only in sodium valproate group.

Table 2: combine effect of sodium valproate and ascorbic acid on pentylenetetrazole-induced seizures in mice (administered 30min. before PTZ injection)

\begin{tabular}{lccc}
\multicolumn{1}{c}{ Groups } & $\begin{array}{c}\text { Seizure latency } \\
\text { (Sec) }\end{array}$ & $\begin{array}{c}\text { Seizure Duration } \\
\text { (Sec) }\end{array}$ & H.L.E \\
\hline Normal Saline $(1 \mathrm{ml} / 100 \mathrm{~g})$ & $214.9 \pm 24.3$ & $12.4 \pm 1.4$ & 0 \\
Sodium valproate $(\mathbf{2 0 0} \mathrm{mg} / \mathrm{kg})$ & $270.6 \pm 41$ & $7.5 \pm 2.3$ & 1 \\
Vitamin C $(100 \mathrm{mg} / \mathrm{kg})$ & $130.9 \pm 10.4$ & $12.9 \pm 1.1$ & 0 \\
Vitamin C (300 mg/kg) & $180.5 \pm 16.6$ & $10.4 \pm 0.4$ & 0 \\
Vitamin C $(100 \mathrm{mg} / \mathrm{kg})$ & & & 0 \\
+ Sodium Valproate $(100 \mathrm{mg} / \mathrm{kg})$ & $418.7 \pm 4.3$ & $2.4 \pm 1.2$ & 0 \\
Vitamin C (300 $\mathrm{mg} / \mathrm{kg})+$ & 0 & 0 & 0 \\
Sodium Valproate $(200 \mathrm{mg} / \mathrm{kg})$ & & & \\
\hline
\end{tabular}

${ }^{*} \mathrm{p}<0.05,{ }^{*} \mathrm{p}<0.001$ when compared to the control group $\mathrm{A}$ and $\mathrm{b}$ represent significant differences with normal saline and sodium valproate respectively. H.L.E - Hind limb extension.

\section{DISCUSSION}

The results showed that ascorbic acid alone has no significant effect on the seizure parameters while sodium valproate $200 \mathrm{mg}$ had protective effect on PTZ-induced seizures. Combination of $100 \mathrm{mg} / \mathrm{kg}$ ascorbic acid and $200 \mathrm{mg} / \mathrm{kg}$ sodium valproate and that of $300 \mathrm{mg} / \mathrm{kg}$ ascorbic acid with $200 \mathrm{mg} / \mathrm{kg}$ sodium valproate administered 15 and 30 minutes respectively prior to PTZ administration had a significant $(p<0.05)$ synergistic and marked protective effect as indicated by an increase in the latency of seizure and reduction in seizure duration as compared to the control. 
This result is in agreement with the finding of Schneider et al., (2004) who reported that vitamin C when used alone did not have any protective effect against acute PTZ-induced. This is because the biological effects of reactive oxygen species (ROS) are successfully controlled by endogenous defense system of antioxidant enzymes and non-enzymatic antioxidants such as vitamin C (Barnham et al., 2004). The central nervous system, namely neurons, are particularly vulnerable to the destructive effects of reactive species (Martinc et al., 2012). Reactive oxygen species can cause deleterious effects on cells through acting on signalling pathways or through causing nonspecific oxidative damage to biomacromolecules (Halliwell and Gutteridge, 2007). Sawicta-Glazer and Czuczwar (2014) reported that ascorbic acid, as an antioxidant and electron donor accumulated in central nervous system, seems to take part in diminishing reactions of oxidative stress in brain and cooperate with other antioxidants like alpha-tocoferol. Vitamin C, easily transported through the blood-brain barrier, is proved to reduce injury in the hippocampus during seizures and acts as a neuroprotective factor by consolidating cell membranes and decreasing lipid peroxidation. Ascorbic acid pre-treatment has been further shown to increase hippocampal superoxide dismutase and catalase activities, increase in the latency to first seizures, suppression of behavioural seizure episodes, and decrease in lipid peroxidation, nitrite content, brain damage, severity of hippocampal lesions, and mortality of rats (Santos et al., 2009; Santos et al., 2008). These findings are a consequence of ascorbic acid free radicals scavenging abilities, which support its neuro-protective activity (Santos et al., 2009). From the study, vitamin $C$ administered alone did not affect seizure activities. This may be due to the fact that vitamin C produces its effect in a dose-depended manner and so possibly with increase in the doses, a significant effect might be elicited as reported by Paczyski et al. (1990) and Marinbo et al. (1997) that vitamin $C$ shows anticonvulsant property in a dose dependent manner in animals injected with PTZ. Sodium valproate is known to increase the turnover of

\section{REFERENCES}

Barnham, K.J., Masters, C.L. and Bush, A.I. (2004). Neurodegenerative diseases and oxidative stress. Nature Review Drug Discovery, 3(3):205-214.

Barros, D.O., Xavier, S.M., Barbosa, C.O., Silva, R.F., Maia, F.D. and Oliveira, A.A. (2007). Effects of the vitamin $E$ in catalase activities in hippocampus after status epilepticus induced by pilocarpine in Wistar rats. Neuroscience, 420(1):76-9.

Chang, P., Walker, M.C., Williams, R.S. (2014). "Seizure-induced reduction in PIP3 levels contributes to seizure-activity and is rescued by valproic acid". Neurobiology of Disease, 62: 296-306.

Halliwell, B., and Gutteridge, J. M. C. (2007). Cellular responses to oxidative stress: adaptation, damage, repair, senescence and gamma-aminobutyric acid (GABA), thereby potentiating GABAergic functions in some specific brain regions thought to be involved in the control of seizure generation and propagation (Loscher, 2002). Furthermore, the effect of valproate on neuronal excitation mediated by the $\mathrm{N}$-methyl-D-aspartate (NMDA) subtype of glutamate receptors might be important for its anticonvulsant effects. Acting to alter the balance of inhibition and excitation through multiple mechanisms is clearly an advantage for valproate and probably contributes to its broad spectrum of clinical effects (Loscher, 2002; Zupan et al., 1999). Valproate has recently been shown to protect against a seizure-induced reduction in phosphatidylinositol $(3,4,5)$-trisphosphate(PIP3) as a potential therapeutic mechanism (Chang et al., 2014).

\section{CONCLUSION}

It was concluded, that the concomitant administration of low dosage of Vitamin $C$ and sodium valproate produces a synergistic anticonvulsive effect in mice. The ability of antioxidants to reduce the seizure manifestations further supports a role of free radicals in seizures and highlights a possible role of antioxidants as adjuncts to antiepileptic drugs for better seizure control.

\section{Conflicts of Interest}

The authors declare that there is no conflict of interests regarding this publication.

\section{Acknowledgements}

The authors are grateful to Ahmadu Bello University, Zaria, Kaduna State, Nigeria and staff of the Department of Human Physiology and neurobehavioral laboratory for supporting the work.

Contribution of Authors'

Alhassan/Mohammed: Experimental design, concept, neurobehavioral studies, practical experimentation and manuscript preparation.

Saleh/Mshelia: Neurobehavioural studies, data analysis and manuscript review.

Yarube : Neurobehavioural analysis and review of manuscript.

Lawan: Standardization and administration of drugs, review of manuscript.

\section{death. Free radicals in biology and} medicine, 4, 187-267.

Jessica, G., Clarissa, V.,Ana, C.B.G., Thaize, L.S., Naieli, S.S., Mayara, L.F., Ana, F.F.A., Roberto, S.S. and Mauro, S.O (2016). Rosmarinic acid is anticonvulsant against seizures induced by pentylenetetrazol and pilocarpine in mice. Epilepsy and Behavior, volume 62: 27-34.

Loscher, W. (2002). Basic pharmacology of valproate: a review after 35 years of clinical use for the treatment of epilepsy. Central Nervous System Drugs. 16(10)-669-94.

Marinbo, M.M., de Bruin, V.M. and de Sousa, F.C. (1997). Inhibitory action of calcium channel blocker sodium valproate on seizures and brain damage induced by pilocarpine and lithium-pilocarpine in rats. Neuropharmacology, 27: 451-458. 
Martinc, B., Grabnar, I. and Vovk, T. (2012). The role of reactive species in epileptogenesis and influence of antiepileptic drug therapy on oxidative stress. Current Neuropharmacology, 10(4):328-343.

Morimoto, K., Fahnestock, M. and Racine, R.J. (2004). Kindling and status epilepticus models of epilepsy: Rewiring the brain. Progress in Neurobiology, 73: 1-60.

Nikalje, A.G., Altamash, A. and Ghodke, M.S. (2012). Herbal Anticonvulsant Agents. A Brief Review. International Journal of Research in Pharmacy and Science, 2 (3) 1-13.

Paczyski, R.P., Meyer, F.B. and Anderson, R.E. (1990). Effects of the dihydropyridine calcium channel antagonist nimodipine on kainic acid- induced limbic seizures. Epilepsy Research 6(1): 33-38.

Patil, C.D. Ahire, Y.S., Pathade, P.A., Pathade, V.V. and Mali, P.R. (2011). Free Radicals, Epilepsy and Anti-oxidant: An Overview. International Research Journal of Pharmacy. 2(2), 64-71.

Santos, I., Tomé, A., Saldanha, G., Ferreira, P., Militão, G. and Freitas, R. (2009). Oxidative stress in the hippocampus during experimental seizures can be ameliorated with the antioxidant ascorbic acid. Oxidative Medicine and Cellullar Longevity, 2:214-21.

Santos, L.F., Freitas, R.L., Xavier, S.M., Saldanha, G.B. and Freitas, R.M. (2008). Neuroprotective actions of vitamin $C$ related to decreased lipid peroxidation and increased catalase activity in adult rats after pilocarpine-induced seizures. Pharmacology, Biochemistry and Behaiourv. 89(1):1-5.

Sawicta-Glazer, E and Czuczwar, S.J. (2014). Vitamin C: a new auxiliary treatment of epilepsy. Pharmacology Reports. 66:4, 529 -33.

Schneider, O.M., Flavia, F.A., Freira, Royes, L.F., and Mello, C.F. (2004). Ascorbate modulates pentylenetetrazole induced convulsion biphasically. Neuroscience, 128 (4): 721-728

Shannon, H.E. and Love, P.L. (2007). Effects of antiepileptic drugs on learning as assessed by a repeated acquisition of response sequences task in rats. Epilepsy and Behavior, 10: 16-25.

Sudha, K., Rao, A.V. and Rao, A. (2001). Oxidative stress and antioxidants in epilepsy. Clinical Chemistry Acta. 303:19-24.

Tawfik, M.K. (2011). Coenzyme Q10 enhances the anticonvulsant effect of phenytoin in pilocarpine-induced seizures in rats and ameliorates phenytoin-induced cognitive impairment and oxidative stress. Epilepsy and Behavior, 22: 671-677.

Weintraub, D., Buchsbaum, R., Resor, S.R. and Hirsch, L.J. (2007). Psychiatric and behavioral side effects of the newer antiepileptic drugs in adults with epilepsy. Epilepsy and Behavior, 10: 105-110

Zupan, G., Erakovic, V., Simonic, A. and Kriz, J. (1999). The influence of sodium valproate on the brain fatty acid level in rats with penicillin-induced seizures. Neuropsychopharmacology, Biology and psychiatry, 23 (5): 951-961 